\title{
CASO DE DOENÇA DE CHAGAS OBSERVADO DESDE O PERIO- DQ INICIAL DA INFECÇÃO, COM APARECIMENTO PRECOCE DE MEGAESÔFAGO E MEGACOLO *
}

\author{
Anis Rassi **, Joffre Marcondes de Rezende ** e Jarbas Doles ***
}

Os autores relatam o caso de uma paciente por êles acompanhada desde o periodo inicial da infecção chagásica até o óbito, num período de cinco anos.

Apresentou, durante o periodo inicial, manifestacões radiológicas e eletracardiográficas de comprometimento cardiaco, espontâneamente reversíveis, nāo mais sendo observadas ao fim de 16 meses.

Posteriormente, desenvolveu a forma digestiva da doença, tendo os sintomas de aperistalsis do esôfago se iniciado cêrca de quatro meses após o periodo inicial da infecção, e os de megacolo, cêrca de quatro e meio anos.

Faleceu no pós-operatório de retossigmoidectomia. Os principais dados de necropsia consistiram em dilatação do esôfago $e$ do colo sigmóide, infiltrado inflamatório ao nivel da musculatura do esôfago, jejuno, ileo, sigmóide e coração, bem como acentuada diminuição do número de neurônios ao nível da musculatura esofagiana. Não foram encontrados ninhos de leishmânias.

Regra geral, as manifestações do periodo inicial da doença de Chagas regridem espontâneamente, entrando 0 paciente numa fase de cura aparente, à qual se chama de forma crônica indeterminada, latente, subclínica ou de infecção inaparente. Posteriormente, podem surgir as manifestações que consubstanciam as demais formas clínicas, como a cardíaca e a digestiva.

A duração do período assintomático, bem como as condiçōes intrínsecas e extrínsecas que favorecem o aparecimento das formas crônicas sintomáticas constituem algumas das incógnitas existentes quanto à evolução da moléstia.

Segundo Laranja \& col. (6), cêrca de 10 a 20 anos após a fase aguda da infecção é que aparecem as manifestações da fase crônica. Às vêzes apresentam-se mais precocemente e, noutras, mais tardiamente, podendo ocorrer também que, mesmo de- corridos muitos anos, não sejam observadas, havendo indício, conforme assinalou Prata (7), de que muitos casos permanecem indefinidamente na forma indeterminada. Vale dizer que a paciente em quem Carlos Chagas descreveu pela primeira vez a doença, decorridos 52 anos, foi exaustivamente examinada por Salgado \& col. (14), não sendo encontradas manifestações imputáveis à moléstia, embora apresentasse xenodiagnóstico positivo.

Dias \& Dias (3) reviram 50 pacientes com período inicial de infecção conhecido, tomados ao acaso dentre 340 , nos quais o tempo médio de doença foi de 16,2 anos. Encontraram 15 na forma subclínica, 15 com a forma cardíaca, 7 com a forma digestiva e 13 com associação das formas cardíaca e digestiva. Dos 28 casos de comprometimento cardíaco, em 8 ocorreu persistência e evolução do processo iniciado na fase aguda e em 20 houve instalação

(*) Trabalho apresentado no Primer Congreso de Medicina Tropical del Cono Sur, realizado em Buenos Aires, de 21 a 24 de agôsto de 1966 .

(**) Do Departamento de Clínica Médica da Faculdade de Medicina da Universidade Federal de Goiás. (***) Do Departamento de Patologia da Faculdade de Medicina da Universidade Federal de Goiás. 

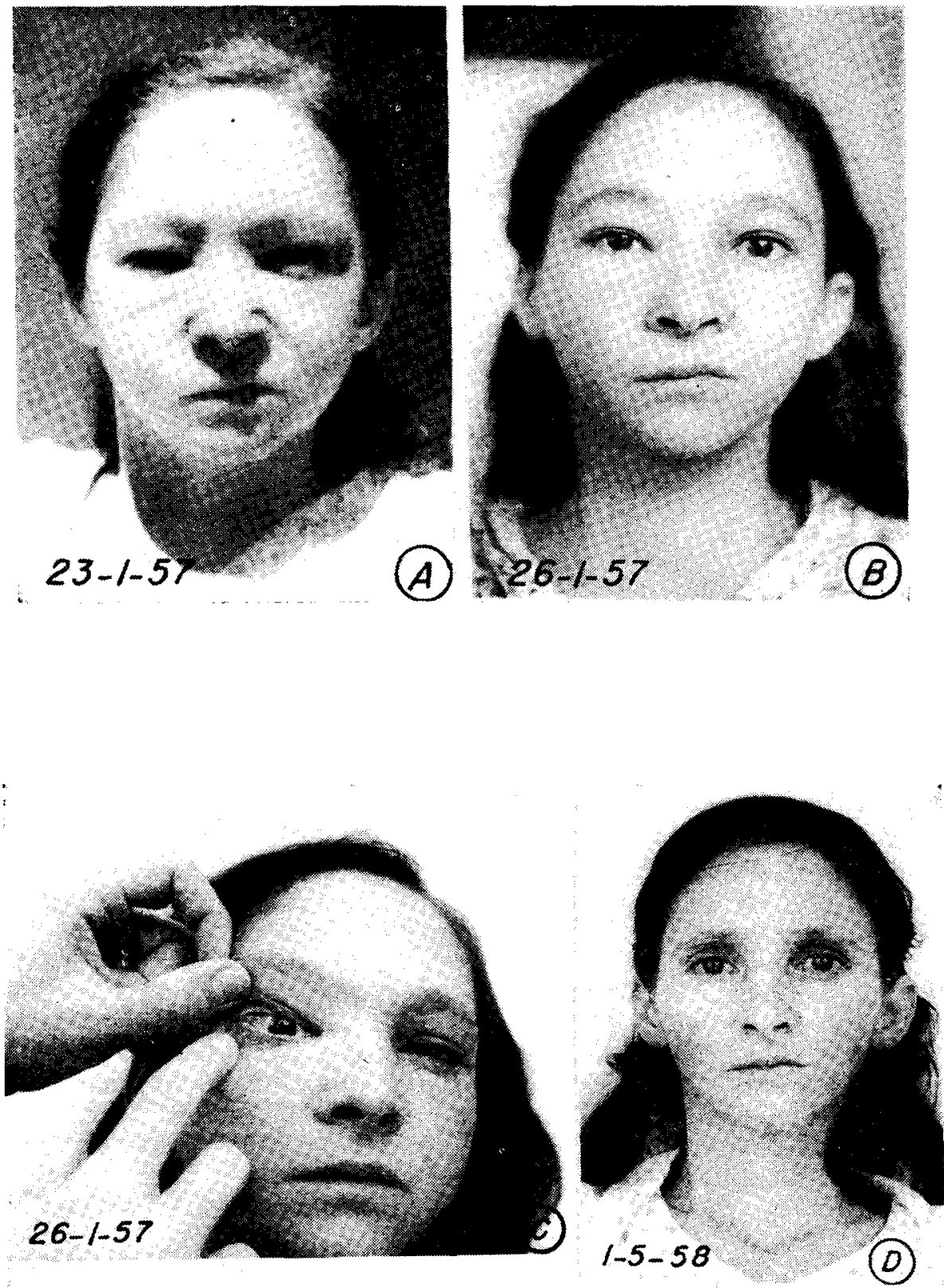

Fig. 1 - As fotografias A, B e C foram obtidas durante o periodo inicial da doenca de Chagas. A: nota-se edema facial generalizado, principalmente a 1$)$. B: observa-se edema apenas na hemiface $D$, sendo bem evidenciado o de ambas as pálpebras. C: dacriadenite. 1): fotografia obtida por ocusiáo do quadro de obstruçáo incompleta do esôfago distal por bòto

alimentar, em virtde de aperistalsis grall 1; facies de emagrecimento e desidralacăo. 
da cardiopatia após um período médio de 13,2 anos. Dos 20 casos de comprometimento digestivo, 15 eram de megaesôfago (com sintomatologia iniciada 13,1 anos, em média, após o período inicial) e 5 correspondiam a colopatia, surgida, em média, aos 18,2 anos de doença.

Dentre os pacientes que vimos acompanhando desde o periodo inicial dá doença de Chagas, tivemos um em que a marcha do processo crônico foi mais rápida que a habitual e cuja divulgação julgamos oportuna.

\section{DESCRIÇÃO DO CASO *}

Trata-se da paciente E.R.S., branca, solteira, com 24 anos de idade, natural do Município de Inhumas (GO) e aí residente.

Procurou-nos inicialmente em 23-1-57, contando que sua doença já durava 36 dias. Amanheceu com a pálpebra inferior direita edemaciada e vermelho-arroxeada, passando a apresentar, alguns dias após, febre alta, de aparecimento vespertino, bem como hiporexia, astenia e dor nas pernas. Por volta do $6 .^{\circ}$ dia de doença notou o aparecimento de edema facial generalizado, principalmente à direita, mais pronunciado pela manhã, bem como em tôda extensão dos membros inferiores. Medicada por farmacêutico, com Lypyopen e vitaminas, nāo melhorou. No $17 .^{\circ}$ dia de doença, ainda com as manifestações referidas ,foi internada em hospital de seu município, tendo sido medicada com Glipex, Metiocolin, Prinachol, Hepavitose, Dibyotil e Bristaciclina; permaneceu internada durante 10 dias tendo obtido melhora gradativa do quadro; a febre cedera e o edema diminuira, principalmente o dos membros inferiores.

Dentre os antecedentes, referiu-se a sarampo e coqueluche na primeira infância, quadro febril aos 13 anos, acompanhado de pústulas, edema generalizado e queáa dos cabelos, bem como a operação de catarata, bilateral, aos 23 anos.

Residia em casa de "pau-a-pique", altamente infestada por triatomineos.

Ao interrogatório sintomatológico, nāo se queixou de limitação da capacidade funcional, precordialgia, disfagia e nem de obstipaçāo intestinal.

Ao exame físico foi observado: paciente em regular estado de nutrição, afebril, eupnéica, com 39,7 quilos de pêso e $1,45 \mathrm{~m}$ de altura. Edema facial generalizado, mais acentuado à direita, lado em que é maior a redução da fenda palpebral pelo edema (Fig. 1A), Conjuntivas levemente descoradas. Pupilas de contornos iregulares. Gânglio pré-auricular palpável à direita, móvel, indolor, do tamanho de um grão de milho e de consistência algo aumentada. Jugulares nāo visualizadas. Ritmo cardíaco regular, com freqüência de 80 b.p.m.; bulhas normais; presença de sôpro sistólico no foco mistral, ++ , proto e meso, suave e sem irradiação. Pulso com caracteres normais. P.A. de $110 \times 70 \mathrm{~mm}$. Parede abdominal edemaciada $(+)$. Fígado palpável a três dedos transversos abaixo da reborda costal, na linha hemiclavicular direita, de borda e superficie lisas, consistência normal e levemente doloroso. Baço palpável a dois dedos transversos abaixo da reborda costal, de superfície lisa, consistência normal e levemente doloroso. Presenca de edema mole, frio e indolor nas coxas $(+)$, pernas $(++)$ e pés $(++)$. Gânglios cervicais e axilares não palpáveis; inguinais palpáveis, com caracteres normais.

Foram realizados os seguintes exames auxiliares:

Pesquisa de T. cruzi entre lâmina e laminula no sangue periférico (23-1-57) Negativa.

Xenodiagnóstico (29-1-57) - Negativo.

Reação de Guerreiro \& Machado - Anticomplementar em 23-1-57 e positiva (titulo maior que 2,8) em 4-2-57.

Hemograma (23-1-57) - Hemácias ... 4.250.000; hemoglobina $13 \mathrm{~g} \%$; leucócitos 9.150 ; neutrófilos $40 \%$ (jovens $2 \%$; bastões $1 \%$ e segmentados $37 \%$ ); eosinófilos $4 \%$; basófilos $0 \%$; linfócitos $50 \%$; monócitos $5 \%$; plasmócitos $1 \%$.

Velocidade de sedimentação das hemácias (23-1-57) - $41 \mathrm{~mm}$ na 1. ${ }^{\mathrm{a}}$ hora (Westergreen, sem correção)

Eletroforese em papel das proteinas séricas (23-1-57) - Albumina 36,98\%; globulinas: alfa, $1,98 \%$; alfa., $3,96 \%$; beta $3,40 \%$; gama 53,68\%. Proteínas totais $5,4 \mathrm{~g} \%$

Provas de labilidade protéica (23-1-57) - De turvação: timol 12 un.; diluição 11 un.; sulfato de zinco 21 un.; sulfato de cádmio +++ . De floculação: timol $+\frac{+}{+}+$; lugol +++ ; cefalina-colesterol +++ ; sulfato de zinco +++ ; diluição +++ . Formol-gel negativa. 

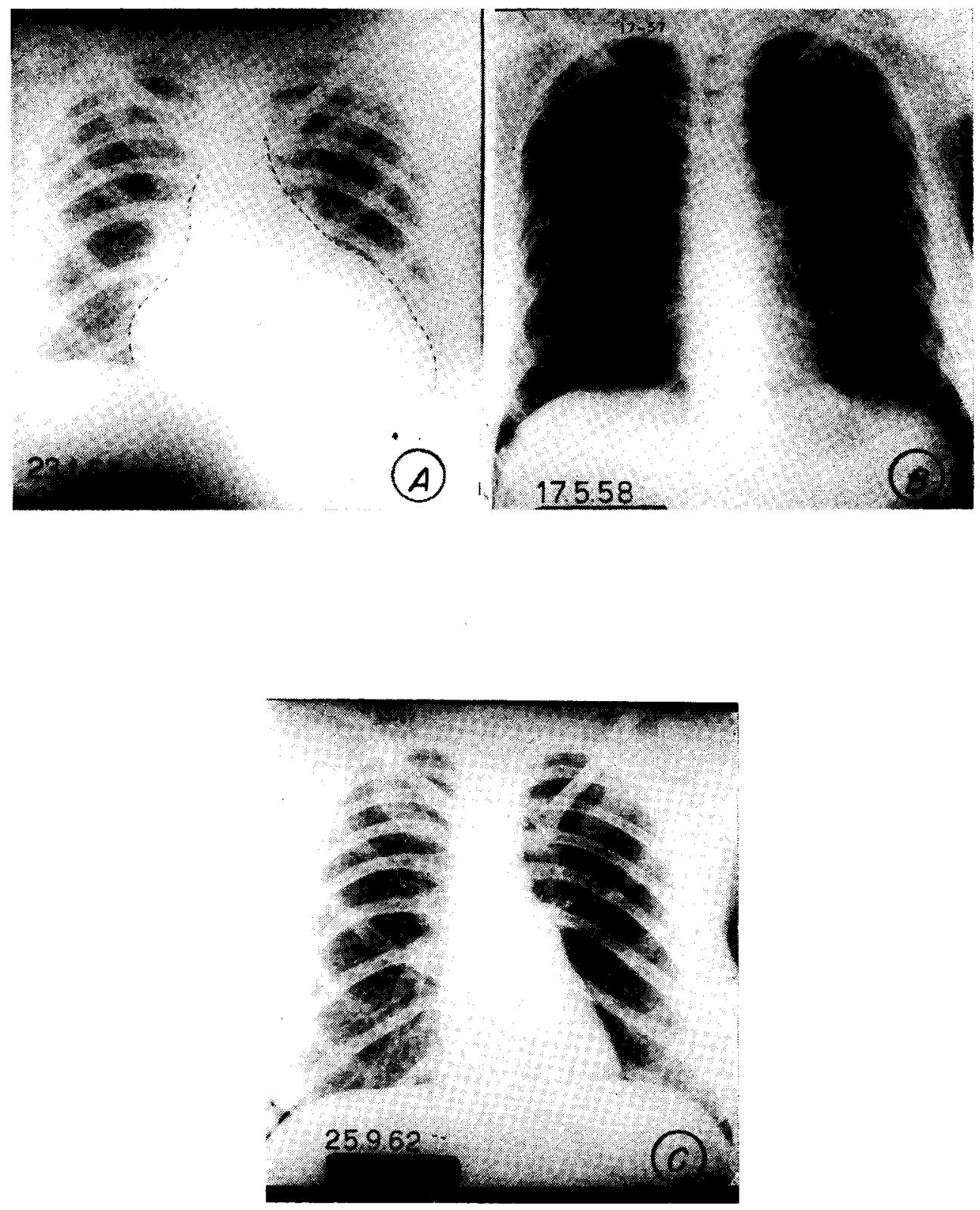

Fig 2 -- A: radiografia obtida durante o periodo inicial da doenca de Chagas; obseria-se grande aumento global do volume cardiaco. B e C: exames praticados na fase crônica da doenca; a área cardiaca se apresenta normal. 
Punção-biopsia de fígado (27-1-57) Os cortes examinados revelam um fragmento de fígado com a estrutura lobular bem conservada. $O$ teor de glicogênio das células hepáticas é reduzido. $\mathrm{Na}$ periferia dos lóbulos as células mostram infiltração gorda. Nos espaços-porta encontra-se uma infiltração celular, em algumas áreas mais pronunciada, constituída por linfócitos, monócitos e histiócitos mobilizados; êsses focos também se acham em tôrno das veias sublobulares, às vêzes tornando irreconhecíveis essas pequenas veias. Num espaço- porta a reação celular é muito intensa, não havendo, porém, formação de granulomas. As células de Kupffer estão aumentadas de volume e em número e nos capilares há um aumento de células linfo-leucocitárias. Diagnóstico: reação inflamatória do figado (chagásica?). Prof. F. Köberle.

Urina tipo $I$ (23-1-57) - volume de 95 $\mathrm{ml}$; densidade de 1022 ; reação ácida; auséneia de elementos anormais; presença de células epiteliais das vias inferiores; leucócitos 2 por campo.

$R X$ - tórax (23-1-57) - Campos pleuro-pulmonares de transparência normal. Nota-se grande aumento global do volume cardíaco (Fig. 2A).

Eletrocardiograma (23-1-57) - O traçado mostra alteração difusa da repolarização ventricular, tipo isquemia subepicárdica (Fig. 3A).

- Tempo braço - língua com Decholin (23-1-57) - 9 segundos.

Pressão venosa na prega do cotovelo $D$ (23-1-57) - 9,8 cm (citrato).

$R X$ - esôfago (25-1-57) — Esôfago de calibre, forma e dimensões normais; trânsito processando-se livremente. Prova de retenção negativa (Fig. 4A).

\section{EVOLUÇÃO}

A paciente fói internada no Hospital Rassi em 23-1-57, sendo medicada apenas com sulfato ferroso, vitaminas e sais minerais fazendo uso de dieta livre. Evoluiu sem febre, tendo ocorrido rápida regressão do edema; em 26-1-57 o edema facial estava presente apenas à direita, evidenciando-se bem $\rho$ de ambas as pálpebras dêsse lado (Fig .1B), bem como a existência de dacriadenite (Fig. 1C); em
28-1-57 não mais era notado edema na parede abdominal e nem nos membros inferiores. Recebeu alta hospitalar em .... 4-2-57, em boas condições, pesando 37,7 quilos, com leve grau de edema hemifacial à direita e com a hépato-esplenomegalia inalterada.

Em 1-5-58 acorreu novamente à consulta. Apresentava-se bastante emagrecida e desidratada (Fig. 1D), com quadro de obstrução incompleta do esôfago distal por bôlo alimentar (Fig. 4B). Informou que desde abril de 1957, vinha apresentando disfagia para alimentos de consistência sólida e que fazia 10 dias que nāo conseguia deglutir nem mesmo líquidos. Com uma sonda de Hurst o bôlo alimentar foi deslocado para o estômago, realizando-se, então, nôvo exame radiológico do esófago (Fig. 4C), que revelou ausência de peristaltismo e prova de retenção positiva (aperistalsis grau I). Dois dias após a paciente foi submetida à dilatação da cárdia com balão penumático, beneficiando-se subjetivamente. Nessa ocasiāo não mais era notada a hépato-esplenomegalia e o exame radiológico do coração (Fig. $2 \mathrm{~B}$ ), bem como o eletrocardiograma (Fig. 3B), estavam normais

Em 16-9-62 voltou novamente para exame ,tendo informado que, além da disfagia, vinha apresentando, desde um ano antes, constipação intestinal, passando até 15 dias sem defecar. Tinha o abdómem timpânico. O estudo radiológico levado a efeito ,então, evidenciou aumento de calibre do esôfago (aperistalsis grau II), com esofagite terminal (Fig. 4D), área cardiaca normal (Fig. 2C), megacolo (Fig. 5) e trânsito intestinal normal.

Em 4-12-62 foi submetida à retossigmoidectomia, vindo a falecer no $3 .^{\circ}$ dia de pós-operatório, em conseqüência de peritonite.

Foram os seguintes os principais dados do exame necroscópico

Esôfago: moderadamente dilatado, com mucosa integra. $O$ exame microscópico mostrou a presença de infiltrado linfocitório intersticial e focal ao nivel da musculatura, que se extende até o plexo de Auerbach. Raríssimos neurônios; a contagem dos mesmos, feita em anéis de 1 $\mathrm{mm}$, revelou a presença de $\mathrm{um}$ ao nivel do $1 / 3$ superior, três ao nível do $1 / 3$ médio e dois ao nível do $1 / 3$ inferior (Fig. 6). 
(A)
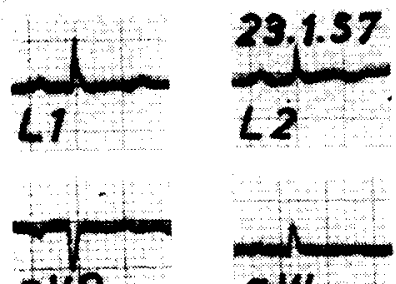
âR

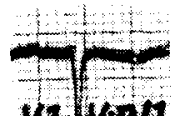
vilna

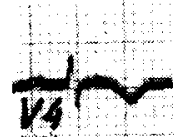

Fig. $3 \quad-1$ rono difusio

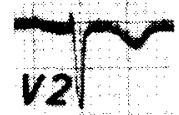

(B)


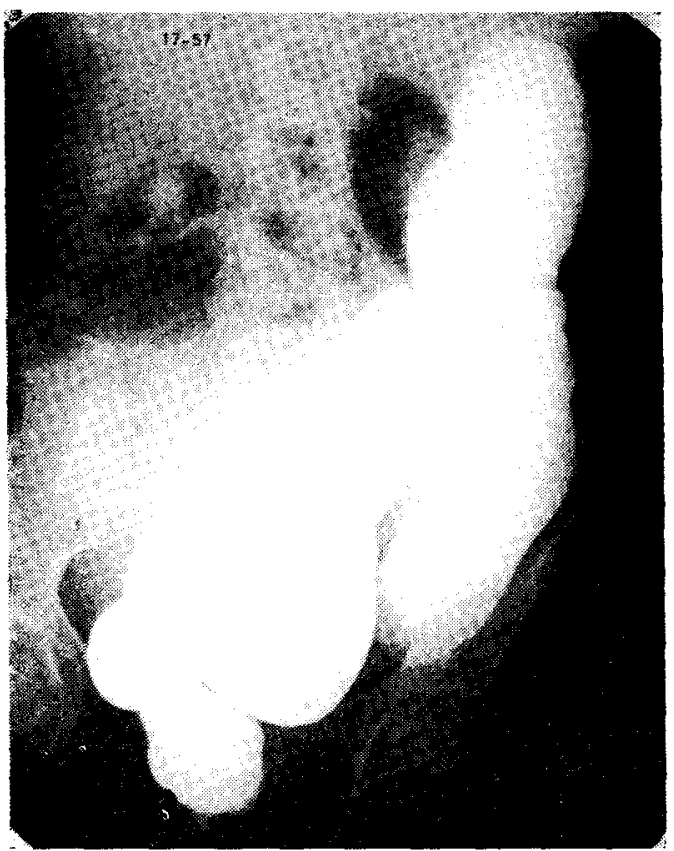




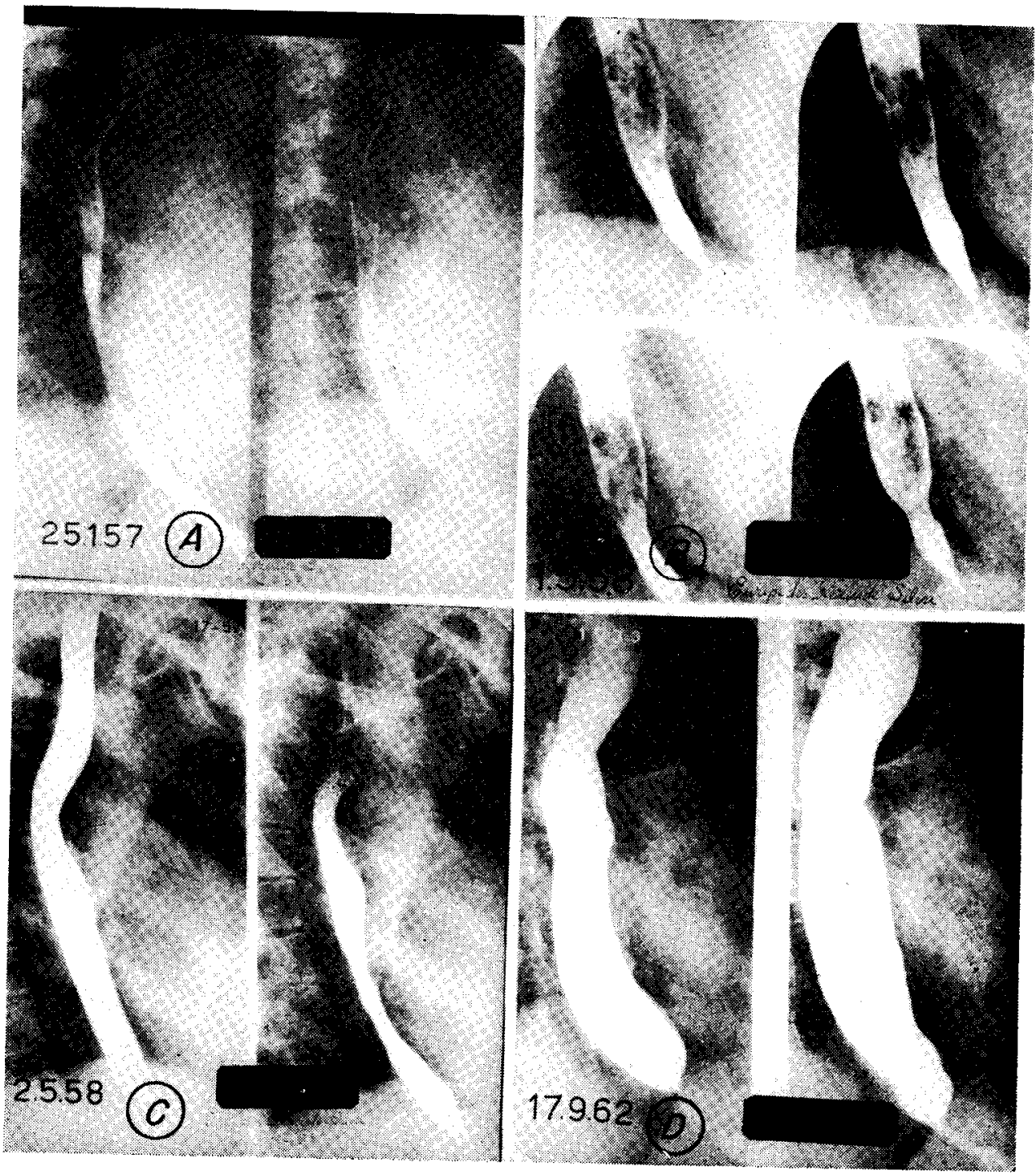

Fig. 4 - A: esôfago morfológica e dinamicamente normal no periodo inicial da doenca. deslocamento do bôlo alimentar esôfago distal por bôlo alimentar. C: radiografia obtida após

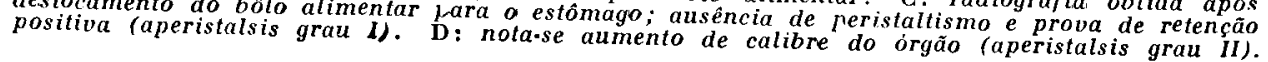






Fig. 6 - Esśfago. A: aspecto panorâmica com a zona do plexo de Auerbach despovoada de neurônios. B: com maior aumento nôta-se plexite com ausência de neurônios. 
Jejuno, ileo e sigmóide: sigmóide dilatado. Jejuno e íleo de calibre normal. Quadro histológico semelhante ao do esôfago. Foram contados, em anéis de $1 \mathrm{~mm}, 302$ neurônios ao nível do jejuno e 447 ao nível do sigmóide (Fig. 7).

Coração: de tamanho normal, pesando $150 \mathrm{~g}$. Quadro de atrofia gelatinosa do epicárdio. Ausência de lesão oro-valvular e de trombose. Foram feitos cortes interessando as paredes das auriculas, dos ventrículos e das auriculetas, bem como do septo interventricular; encontrou-se discreto grau de edema intersticial e infiltrado intersticial difuso, predominantemente linfoplasmocitário, mais intenso ao nível de ventrículo esquerdo, onde foram observadas, ainda, áreas de miocitólise. Não foram evidenciados ninhos de leishmânias (Fig. 8) .

\section{COMENTÁRIOS}

Consideramos como próprio do período inicial da doença de Chagas o quadro apresentado pela paciente. Com efeito, a febre, o edema, a hépato-esplenomegalia e os sinais oculares (edema bipalpebral unilateral, dacriadenite e hipertrofia ganglionar satélite) constituem manifestações clínicas cardinais dêsse periodo. Sob o ponto de vista laboratorial, realçamos a existência de linfocitose, bem como de hipoproteinemia total com hipoalbuminemia e hipergama-globulinemia, que são alteraçōes bastante freqüentes no referido período (15) . Os aspectos eletrocardiográfico e radiológico do coração, típicos de uma pericárdio-miocardite aguda, são dados que reforçam o diagnóstico. A biopsia hepática revelou, igualmente, alterações histológicas encontradas em casos de fase aguda da doença de Chagas (10).

Tais considerações são formuladas para justificar o diagnóstico de período inicial da infecção chagásica face à negatividade da pesquisa do $T$. cruzi ao exame direto e através do xenodiagnóstico. Com respeito a êsses exames, cumpre salientar que foram realizados apenas uma vez, decorrido mais de um mês do início das manifestações, e que a pesquisa do $T$. cruzi toi feita entre lâmina e lamínula, condições estas que limitam a detecção do parasito. Acresce dizer ainda que mesmo o xenodiagnóstico negativo não invalida $o$ diagnóstico, embora saibamos de sua elevada sensibilidade no período inicial da infecção; para exemplificar, lembramos que, em publicação anterior (9) assinalamos a ocorrência de um caso agudo, confirmado pela positividade do exame direto entre lâmina e lamínula, no qual o xenodiagnóstico foi negativo no $34^{\circ}$ dia de doença; não bastasse êste exemplo, temos c de outro caso (não publicado) em que paradoxalmente - enquanto o exame direto entre lâmina e lamínula mostrou-se positivo, resultou negativo o xenodiagnóstico praticado no mesmo dia. Cibservação semelhante foi feita por Dias (2) e Dias \& Dias (5), que assinalaram a ocorrência de alguns xenodiagnósticos negativos, nāo cbstante terem sido efetuados no mesmo dia em que o exame a fresco do sangue resultara positivo.

Destacam-se, no caso, dois fatos. De um lado, a existência de importantes manifestações de cardiopatia (radiológicas e eletrocardiográficas) no periodo inicial da infecção, em contraste com a pequena expressāo do comprometimento cardiaco na fase crônica. De outro lado, a precocidade do aparecimento de megaesôfago e megacolo.

Constitui ainda uma lacuna, nos estudos da doença de Chagas, o conhecimento da verdadeira incidência de manifestações digestivas em uma população chagásica, dos fatôres condicionantes de seu desenvolvimento, bem como do tempo de evolução entre a fase aguda e o aparecimento do megaesôfago e megacolo, expressões máximas da desnervação intramural do tubo digestivo.

No tocante à incidência, deve ser levada em conta a área geográfica estudada, pois, do mesmo modo que a forma cardiaca, a forma digestiva é freqüente no Brasil Central, parecendo serem raras no sul do País, embora os índices de prevalência da infeccão chagásica sejam semelhantes $(23,5 \%$ e $23,88 \%$, respectivamente) em ambas as regiões consideradas ( 1 e 13 ).

Inquérito radiológico do trânsito esofágico por meio de abreugrafia foi realizado no Estado da Bahia por Prata, Almeida \& Macedo (8), os quais, examinando 1.082 pessoas de área enđêmica de doença de Chagas, encontraram retardo do esvaziamento em $29 \%$ dos casos, ao passo que, o 


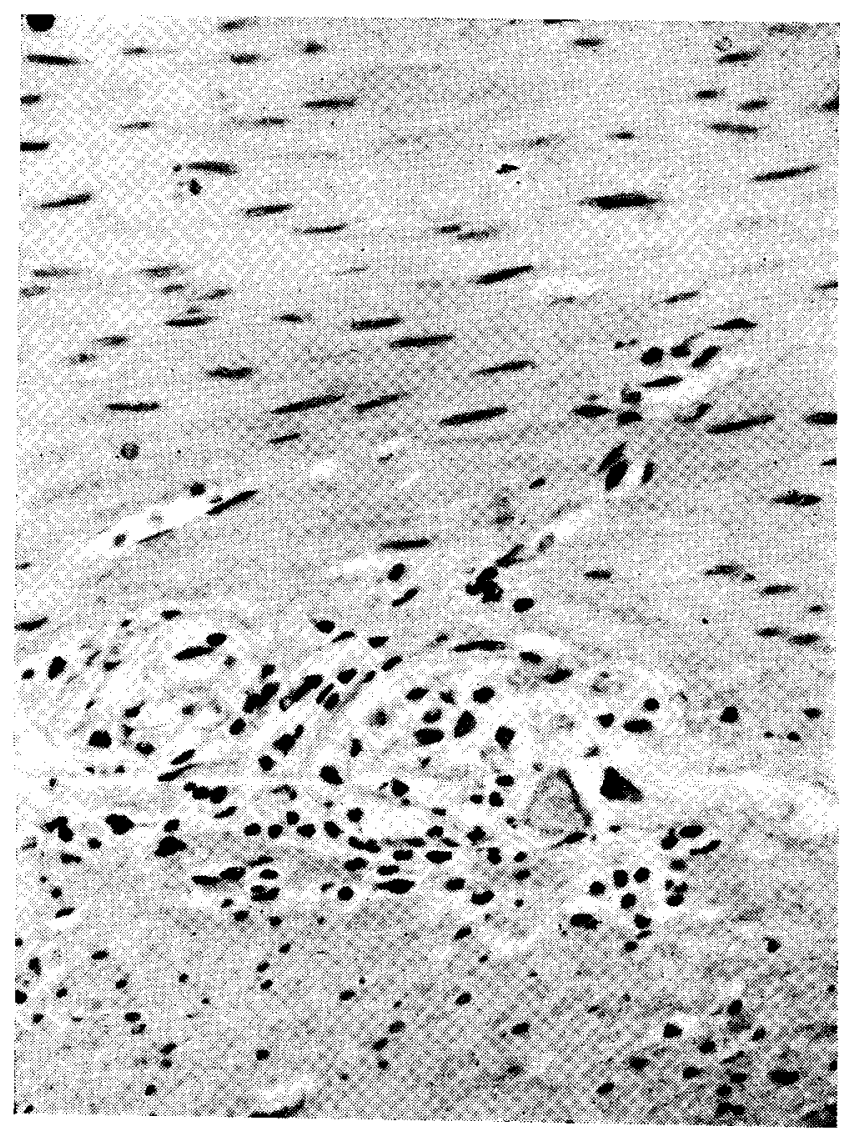

Fig. 7 --. Cólon sigmóide. Plexite com apenas um neurônio, degenerado. 


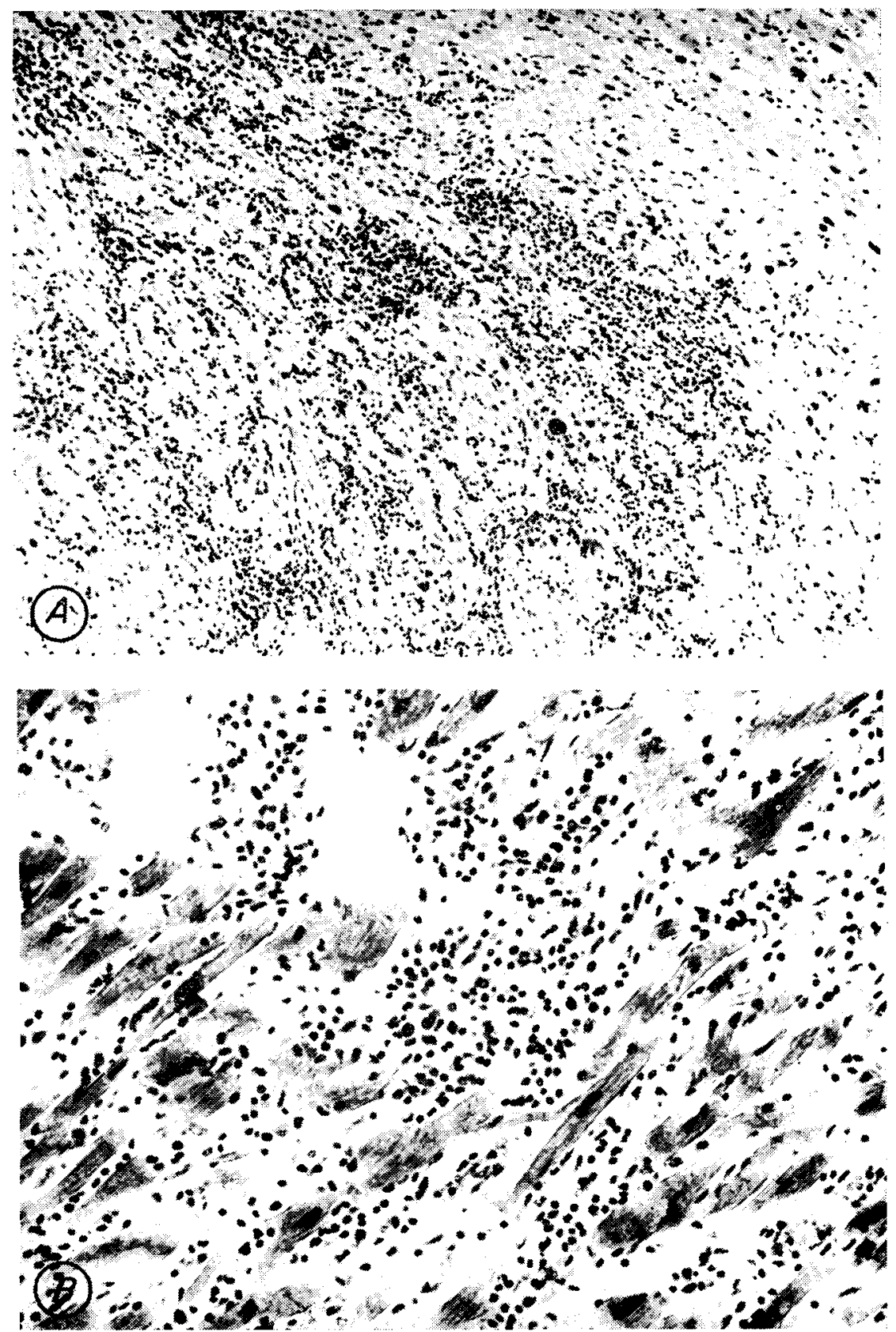

Fig. 8-Coração. A: nota-se denso infiltrado intersticial por células redondas. B: observa-se edema, infiltrado intersticial por células redondas $e$ discreto gran de miocitólise. 
mesmo inquérito, realizado em 1.300 pessoas de área endêmica de esquistossomose, acusou alteraçāo da cinética esofagiana em apenas $1 \%$ dos casos.

Dias (4), em um inquérito na zona rural de Bambuí (MG), valendo-se apenas da anamnese, registrou seis casos de forma digestiva dentre 40 crianças com menos de 12 anos, com sorologia positiva, o que dá uma percentagem de $15 \%$ para essa faixa etária.

Na revisão de Dias \& Dias (3) a forma digestiva ocorreu em 20 de 50 casos $(40 \%)$ após um tempo médio de observação de 16,2 anos.

Quanto aos fatôres que condicionam a evolução da doença, muito se tem especulado sôbre o estado nutricional dos pacientes, seui estado imunobiológico, cêpas de tripanosoma, etc; porém, na realidade, pouco ou nada se conhece a respeito do problema.

O tempo de evolução entre a fase aguđa da doença de Chagas e o aparecimento da 'orma digestiva parece ser extremamente variável. O simples encontro de casos de megaesôfago em crianças de baixa idade, com menos de cinco anos, indica claramente não ser necessário longo prazo para a exteriorização clínica da esofagopatia (11). Quanto ao megacolo, a experiência tem demonstrado ser necessário um tempo maior para que se desenvolvam as alterações morfológicas decorrentes da incoordenação motora. Contudo, é freqüente observar-se, antes que ocorra a dilatação da sigmóide a ponto de permitir o diagnóstico de megacolo ,a ocorrência de obstipação intestinal e de certa disquesia, conseqüente, ao que parece, à perturbação do reflexo de defecação (12).

O caso presente é bastante ilustrativo da precocidade com que podem surgir as manifestaçōes digestivas da doença de Chagas.

\section{AGRADECIMENTO}

Somos gratos ao Prof. F. Köberle pela realização do exame histopatológico do fragmento de fígado obtido por punçãobiopsia e pela contagem de neurônios.

\section{$S U M M A R Y$}

\section{A FOLLOW-UP CASE REPORT ON CHAGAS' DISEASE FROM THE INITIAL INFECTION WITH EARLY DEVELOPMENT OF MEGAESOPHAGUS AND MEGACOLON}

A follow-up case report on Chagas' disease is presented, from the initial infection through the demise, five years later.

In the early stage of the disease, there was radiologic and electrocardiographic evidence of cardiac involvement, with spontaneous regression up to the siviteenth month.

Aperistalsis of the esophagus developed within 4 months after the initial infectiore, and megacolon $41 / 2$ years later.

The patient died in the postoperative period, following surgery for rectosigmoidectomy.

At autopsy there was dilatation of the esophague and sigmoid colon; the muscle layer of the esophagus, small bowel, sigmoid colon and heart showed inflammatory changes and the number of neurons in the esophageal muscle layer was greatly reduced. Nets of leishmania could not be found.

\section{BIBLIOGRAFIA}

1 - BRANT, T.C. - Razões para nova orientação nas pesquisas sôbre doenca de Chagas no Estado do Rio Grande do Sul. Rev. Bras. Malariol. D. Trop., 8: 105-112, 1966.

2 - DIAS, E. - Informações acêrca de 300 casos de doença de Chagas com periodo inicial conhecido, fichados no Centro de Estudos de Bambuí. O Hospital, 47: 647-653, 1955.
3 - DIAS, E. \& DIAS, J.C.P. - Notas sôbre a evolução da doença de Chagas humana em Minas Gerais. In: Resumo trab. apresentados III Cong. Soc. Bras. Med. Trop., Salvador, 1967, p. 27.

4 - DIAS, J.C.P. - Prevalência da doença de Chagas entre crianças da zona rural de Bambui, MG, após ensaio profilático. Rev. Bras. Malariol. D. Trop., 19: 135-159, 1967. 
5 - DIAS, J.C.P. \& DIAS, E. - Doença de Chagas; consideraçōes gerais acêrca de 67 casos humanos de doenca de Chagas aguda observados pelo Pôsto Dr. Emmanuel Dias (Instituto Oswaldo Cruz), Bambuí, MG, entre 1955 e 1967. O Hospital, ... 73: $1935-1945,1968$.

6 - LARANJA, F.S.; DLAS, E.; NÓBREGA, G. \& MIRANDA, A. - Chagas' disease. A clinical, epidemiologic, and pathologic study. Circulation, 4: 1035-1060, 156.

7 - PRATA, A. - Prognóstico e complicaçóes da doença de Chagas. Rev. Goiana Med., 5: 87-96, 1959.

8 - PRATA, A.; ALMEIDA, F. \& MACÊDO, V. - Estudo comparativo sôbre o esvaziamento do esôfago pela abreugrafia entre uma área endêmica de doenca de chagas e outra de esquistossomose. In: Resumo trab. apresentados III Cong. Soc. Bras. Med. Trop., Salvador, 1967, p. 39 .

9 - RASSI, A.; BORGES, C.; REZENDE, J.M. de; CARNEIRO, O.; SALUM, J .; RIBEIRO, I.B. \& PAULA, O.H. de - Fase aguda da doenca de Chagas; aspectos clínicos observados em 18 casos. Rev. Goiana Med., 4: 161-189, 1958.
10 - REZENDE, J.M. de - Alterações hepáticas na fase aguda da doenca de Chagas. In: Programa IX Cong. Bras. Gastrenterologia, Rio de Janeiro, 1957, p. 55 .

11 - REZENDE, J.M. de - Forma digestiva da moléstia de Chagas. Rev. Goiana Med., 5: 193-227, 1959.

12 - REENDE, J.M. de - Etiopatogenia do megacolo adquirido. An. I Cong Latino-Americano, II Internacional e XBrasileiro de Proctologia, ...... 1: 259-268, 1960 .

13 - REZENDE, J.M. de - The endemic South American megaesophagus. Clinical aspects. An. 2nd World Cong. Gastroenterol, 1: 69-74, 1963.

14 - SALGADO, J.A.; GARCEZ, P.N. OLIVEIRA, C.A. de \& GALIZZI, J - Revisão clínica atual do prirnerro caso humano descrito da doença de Chagas. Rev. Inst. Med. trop. São Paulo, 4: 330-337, 1962

15 - SALUM, J . ; IACAZ, P. da S.; BORGES, C.; RASSI, A. \& REZENDE, J.M. de - Eletroforese das proteinas séricas na fase aguda da doença de Chagas; comportamento evolutivo observado em 15 casos. Rev. Goiana Med., 5: 13-21, 1959. 